\title{
Does institutional quality affect the level of entrepreneurial success differently across the entrepreneurship distribution?
}

\begin{abstract}
The phenomenon of entrepreneurship has driven much of the attention of academics, practitioners and policy makers. A correct and deep understanding of all the different conditions affecting entrepreneurship rates will advance in the establishment of useful measures that increase entrepreneurial success. The vast majority of the literature on the effect of institutional quality on entrepreneurship has been investigated based on average effects. However, how the impact of institutional quality on the level of entrepreneurship varies with the conditional distribution of entrepreneurship is still poorly understood. The present study attempts to fill the research gaps in this field. In order to examine the impact of institutional quality on entrepreneurship at different entrepreneurship levels, the fuzzy set Qualitative Comparative Analysis (fsQCA) approach is employed. Results show that entrepreneurial success is determined by the combination of the following conditions of institutional quality: voice accountability, political stability, regulatory quality and rule of law. Implications and future research directions are discussed. It would be interesting to analyze the motivation to become an entrepreneur, both theoretically and empirically, differentiating between opportunity and necessity entrepreneurship.
\end{abstract}

Keywords: Entrepreneurship; Institutional quality; fsQCA; qualitative analysis

\section{Introduction}

Entrepreneurship has become a phenomenon of paramount importance and which has received growing attention in recent years (Pejic Bach et al., 2018; Del Bosco et al., 2019; Kraus et al., 2020). Indeed, not only does increased entrepreneurial activity carry implications for industry competition (Ferreira et al., 2019), but it also exerts a profound influence on economic growth from a wide range of perspectives, such as employment, innovation (Roig-Tierno et al., 2018; Fischer et al., 2019; Ilg, 2019), and welfare effects (Valliere \& Peterson, 2009; Angulo-Guerrero et al., 2017; Ponce et al., 2019). Therefore, a deep understanding of the determinants of entrepreneurship will help the relevant departments to establish effective measures that increase entrepreneurial activity (Semrau et al., 2016), and thereby accelerate economic growth (Kang et al., 2019).

Still, despite the number of studies available on the determinants of entrepreneurship (Nina Gunnerud, 1997; Cuervo, 2005; Stephan \& Uhlaner, 2010), many empirical studies have mainly concentrated on the entrepreneur's individual-level characteristics (Bercovitz \& Feldman, 2008; Bolton \& Lane, 2012; Barron \& Markman, 2018), thus neglecting the influence of the institutional environment on entrepreneurial activity. Since seminal studies like Baumol's (1990) and North's (1990) provide key theoretical insights into entrepreneurial development across different institutional environments, scholars have been paying considerable attention to the role of institutional quality in the cross-national variation of entrepreneurial activity (Nyström, 2008; Sobel, 2008; Díaz-Casero et al., 2012; Aparicio et al., 2016; Asongu et al., 2018). For this reason, we will take as a theoretical basis the definition of institution provided by Douglass North 
(1990). This author claims that institutions are made up of norms and regulations that are expressed in a particular context, both in formal and informal perspectives.

The fostering of entrepreneurial business activities in a particular context have a dependence on the regulations and norms established in that particular region (Parsons, 1990; Bao et al., 2016). This means that institutions determine the levels of entrepreneurial activities in a context. For this reason, Urban et al. (2016) affirm that the laws related to entrepreneurship issues have straight implications on the region's entrepreneurial orientation (Urban, 2016). The economy, and consequently the entrepreneurial process, is an element determined by culture. In other words, every economic process is the consequence of a culture and socialization procedure (Bourdieu, 2011). On the other hand, the entrepreneurial process can be created by need or opportunity. In this sense, the reasons that drive entrepreneurs to constitute a new business idea could vary. As a consequence, the institutional theory that supports the economic activity will be different taking into account that the context in which the entrepreneurial business is created varies (Busenitz et al., 2000).

However, an important deficiency of the existing studies so far has been the assumption that the effect of entrepreneurship on institutional quality is homogenous across different countries (Litschka \& Pellegrini, 2019). In this sense, almost all, if not all earlier studies estimate the average effect of institutional quality on the basis of entrepreneurial activity. However, we should pay attention to the fact that their findings may not be applicable to some countries whose entrepreneurship levels are at the tail of the distribution, since countries showing low and high levels of entrepreneurship are likely to respond differently to factors that spur entrepreneurship activity (Arzubiaga et al., 2018). Furthermore, a recent study by Nikolaev and Wood (2018) gives evidence of contagion effects within entrepreneurship, i.e., it is possible that entrepreneurship operates on a feedback basis. Additionally, economic theory would also suggest that institutional quality effects are likely to vary across countries (Welter \& Smallbone, 2011). In particular, one could theorize that, in terms of contributing to entrepreneurship rates, a more solid institutional quality in countries with high entrepreneurship levels might bring marginal returns different from the ones of those with low entrepreneurship levels. One question, therefore, naturally arises: does institutional quality affect entrepreneurship differently across the entrepreneurship distribution?

This study aims to provide a response to the consequences on entrepreneurship derived from institutional quality. Our study contributes to the literature, first, by the effect of institutional quality on entrepreneurship on the distribution of the response variable (i.e., entrepreneurship); second, by analyzing the effect of the institutional quality index, which was constructed from the fsQCA based on the influences of the specific areas of institutional quality (control of corruption; the rule of law; voice and accountability; regulatory quality; political stability; and government effectiveness), on entrepreneurship. Thus, our study not only supplements the extant literature on entrepreneurship, but also aims to provide evidence of stylized results exceeding the average.

The rest of this article is structured as follows. The next section gives a brief historical review of the institutional quality-entrepreneurship nexus. Section 3 describes the model, data and methodological approach, followed by the presentation of results in Section 4. Lastly, Section 5 concludes by offering some policy recommendations and indicating potential avenues for future research. 


\section{Institutional quality and entrepreneurship}

Institutions represent laws (formal and informal), regulations, and norms (Selznick, 1949; Everett, 1939). These regulations include codes of conduct, behavior and patterns that build the complex construct which determines the human relationships and influence the decision making of companies. According to North (1993), institutions represent the "rules of the game" in an economy, while organizations and entrepreneurs stand for the players. According to Scott (1994), the business and entrepreneurial activities are defined by the institutional framework settled in a society. This institutional framework determined the basic principles which include the regulations, norms and restrictions both in formal and informal aspects regarding political, legal and social matters. In the same line, organizations have to adapt to the standards offered by the institutions, in order to obtain approval from society and institutions (DiMaggio and Powell, 1983). Formal laws are defined as those regulations that are expressed explicitly in written terms. Constitutions are the main example of formal laws. On the other hand, the informal institutions represent the non-explicit norms established in a country. In other words, they are constituted by values, patterns of behavior, traditions and beliefs that shape the culture of a particular context (Escandon-Barbosa et al., 2019; North 1990). The most predominant difference between formal and informal institutions appeal to the form they are found in society. Informal institutions can be tacitly found in a context, whereas formal institutions are expressed literally and integrated explicitly. For this reason, the informal institutions could be subject to personal objections and individual perceptions could arise. As a consequence, the patterns of behavior, conduct and decision-making carried out by individuals, and more specifically, by entrepreneurs, are highly influence by the formal and informal institutions of the particular context to which they belong.

Nevertheless, it is not necessary that formal institutions be in the same line as informal ones. The academics have divided the institutions into three different perspectives, depending on particular characteristics. These three dimensions are: coercitive, regulatory and cultural-cognitive (Urban, 2016; Busenitz et al., 2000; Scott, 2005; North, 1990). It should be highlighted that these three perspectives work simultaneously for a particular context. However, their relevance could vary among institutions. This means that for a specific culture, maybe the coercive institutions are more valid than the cognitive ones, or vice versa. In the same line, according to Scott (2005), the diverse institutional perspectives (regulatory, normative and cultural-cognitive) may not be identical in the same culture. Besides, the influence of some of them could reduce the impact of others.

According to North (1990) and Welter (2005), the main actor of change in society is the entrepreneur. An entrepreneur is the individual in society who identifies a new opportunity in the market and finds the way to satisfy this existing need. In this sense, the opportunity that the entrepreneur foresees appeals as a source of change. For this reason, the institutional approach defined by North (1990) takes into account the definition of entrepreneurship that is generated by opportunity, rather than necessity. The institutions are therefore responsible to adapt their regulations, values, norms and beliefs to these changes generated by the entrepreneurs. External changes in the environment are combined with internal changes carried out inside companies and entrepreneurs, and institutions should adapt their matrices to these new context (Urbano and Alvarez, 2014; Urbano et al., 2019). In cases in which entrepreneurship is generated by opportunity (rather than by necessity), the influence that informal institutions have on the entrepreneur are higher than the influence exerted by formal elements. This is because the social elements ultimately influence the decision of starting a new venture and bringing into being the generation of a new business idea (Escandon-Barbosa et al., 2019). Simultaneously, culture represents a determinant element in developing innovation (Schumpeter, 2000; Gómez-Haro et al., 2011).

In the earlier research available on this subject, scholars generally tend to apply a single, cross-section data treatment. For example, by conducting a cross-sectional study of 22 OECD countries, Sobel et al. (2007) find that institutional 
quality has a positive and significant impact on the overall entrepreneurial activity (Perees et al., 2018). Moreover, they also investigate which specific areas of economic freedom have the largest impact on entrepreneurship. Their results show that regulation and government size are the main areas of economic freedom influencing entrepreneurial activity. Using cross-section data for 29 countries, Bjørnskov and Foss (2008) also indicate that government size is indeed a strong factor determining entrepreneurial activity. However, Nyström (2008) argues that it is crucial to verify their results in a panel data setting, because the use of one-year-period, cross-sectional data does not reflect the impact of unobserved, countryspecific factors such as social norms and mores. Therefore, Nyström (2008) employs the panel data framework to reexamine this issue, and his results seem consistent with the findings of Bjørnskov and Foss (2008) with respect to the effect of government size on entrepreneurship. However, contrary to Bjørnskov and Foss's conclusions (2008), he finds that a less strict regulation, a better legal structure and property rights security tend to have a positive impact on selfemployment. In addition to the overall entrepreneurial activity, many scholars also explore the linkage between institutional quality and entrepreneurship motivation, relying on a classification for types of entrepreneurship which differentiates between necessity and opportunity entrepreneurship on the basis of the GEM framework (Barnett et al., 2019; Shan et al., 2018). Fuentelsaz et al. (2015) explore the effect of the formal institutions on different types of entrepreneurship in a sample of 63 countries for the period of 2005-2012 and find that economic freedom is negatively linked with necessity entrepreneurship, but positively associated with opportunity entrepreneurship. Recent work by Angulo-Guerrero et al. (2017) similarly finds that economic freedom increases opportunity entrepreneurship and decreases necessity entrepreneurship. Moreover, they also investigate further the effect of different areas of economic freedom, compiled by the Fraser Institute, on both types of entrepreneurship motivation.

In short, the above-mentioned studies regard the Fraser Institute's cross-country economic freedom index as a proxy for institutional quality. In this background, economic freedom, understood as the existence of market-economic-oriented institutions, may be considered as an important aspect of entrepreneurship. Since institutions have various dimensions, and there is no universally accepted set of measures for indicators of institutional quality, some studies prefer to use the six governance dimensions of the Worldwide Governance Indicators (WGI) to proxy institutional quality. For instance, Fereidouni and Masron (2012) apply the six dimensions of governance to their study, and their results show that corruption, the rule of law, and political stability (Gonzalez-Garcia et al., 2019) are positively associated with entrepreneurial activities. Herrera-Echeverri et al. (2014), for their part, create a composite index measuring the quality of institutions, representative of the six governance dimensions of WGI in one year, demonstrating that institutional quality has a highly positive impact on entrepreneurship.

In summary, previous studies have successfully linked various indicators of national institutions to different measurement systems for entrepreneurial activity. However, a common empirical approach applied to examine the relationship between institutional quality and entrepreneurship is quantitative regression (Gao et al., 2018). Although the quantitative approach is important, scholars and policymakers are sometimes more concerned with the effects of some explanatory variables on different parts of the distribution of the dependent variable rather than on the mean. Environmentalists are generally concerned about the effect of some determinants of $\mathrm{CO}_{2}$ emissions at different emissions levels (Wu et al., 2015). Similarly, we want to know whether a given institutional quality attribute has a different impact across the distribution of entrepreneurship. Hence, we adopt a fuzzy set Qualitative Comparative Analysis (fsQCA) approach to explore how the effect of institutional quality on the level of entrepreneurship varies in accordance with the conditional distribution of entrepreneurship. 


\subsection{Propositions}

According Kaufmann et al. (2009), The World Bank Project identified six different factors that influence new business generation from the point of view of institutional quality: 1) control of corruption, 2) rule of law, 3) voice and accountability, 4) regulatory quality, 5) political stability, 6) government effectiveness (Friedman, 2011).

\section{Voice and accountability}

Voice and accountability express to what extent the agents of a country or region can take part in deciding the new government. This institutional quality dimension also refers to the ability of citizens to express and associate freely (Friedman, 2011). Thus, the corresponding proposition is as follows:

Proposition 1: The voice and accountability (VA) of a country has an influence on the level of entrepreneurship.

\section{Political stability}

Political stability refers to the probability that the political situation of a particular context will be threatened by violent episodes, or simply destabilized (Friedman, 2011). Therefore, the following proposition could be derived:

Proposition 2: The political stability (PS) affects the entrepreneurship level in a country.

\section{Government effectiveness}

Government effectiveness refers to the level of quality perceived by the society of public services, elaboration and execution of policies and the reliability of the implementation of those practices (Friedman, 2011). The corresponding proposition is as follows:

Proposition 3: Government effectiveness (GE) affects the level of entrepreneurship in a country.

\section{Regulatory quality}

Regulatory quality expresses the capacity of the government to elaborate and execute different practices, regulations and policies that encourage entrepreneurial development (Friedman, 2011). Thus, the following proposition is presented. Proposition 4: Regulatory quality (RQ) influences the level of entrepreneurship in a country.

\section{Rule of law}

The rule of law refers to the different attitudes that a society adopts in terms of following the rules established by institutions, which include respecting rights and obligations, property rights and penalties against crime (Friedman, 2011). Hence, the following proposition is presented:

Proposition 5: The rule of law (RL) established in a country influences the entrepreneurship level of the country.

\section{Control of corruption}

The control of corruption expresses the extent of perceptions that the state power is conducted with the objective of having individual and private benefits (Friedman, 2011). Therefore, the corresponding proposition is as follows:

Proposition 6: The control of corruption (CC) in a country has an influence on the level of entrepreneurship.

\section{Methods}

3.1 Data and model 
We have employed a dataset consisting of 91 countries and regions, which covers the period from 2006 to 2015. Both the countries and the period of interest were selected based on the availability of data. The full list of countries and regions included in this study is reported in Appendix A. The main dependent variable is entrepreneurship, and our main measure of entrepreneurship is new business entry density, which is also denoted as the rate of new company entry (entry density), and based on the number of new companies registered by each 1000 people of working age (using a standard range of $15-64$ years of age).

Concerning institutional quality, there is no universally accepted set of measures for indicators of institutional quality. Here, our data was obtained from the World Governance Indicators (WGI). It covers six dimensions of institutional quality: control of corruption (CC); the rule of law (RL); voice and accountability (VA); regulatory quality (RQ); political stability (PS); and government effectiveness (GE). Since there is a high correlation among these indices (Globerman \& Shapiro, 2002), it may not be appropriate to utilize them all in fuzzy set Qualitative Comparative Analysis (fsQCA). As a result, in order to measure the quality of institutions, and taking as a departing point the study of Herrera-Echeverri et al. (2014), we have employed fsQCA to build the comprehensive institutional quality index (denoted as institutional quality I), which is constructed with these six dimensions of institutional quality indicators (i.e., CC, VA, RL, PS, RQ, and GE).

\subsection{Outcome, causal conditions and calibration}

The outcome is the level of entrepreneurship. It is defined and measured as new business entry density. This ratio can be considered a proxy of entrepreneurship distribution. According to the existing literature, and in order to define the conditions capable of influencing the final new business entry rates, six antecedent conditions have been considered to stem from institutional quality: voice and accountability; political stability; government effectiveness; regulatory quality; the rule of law; and control of corruption. Table 1 provides a source of description for these conditions. 
Table 1. Outcome and conditions: description and codification

\begin{tabular}{|c|c|c|c|}
\hline Type & Name & Description & Codification \\
\hline Outcome & $\begin{array}{l}\text { Entrepreneurship } \\
\text { rate (success) }\end{array}$ & $\begin{array}{l}\text { Amount of newly registered businesses per 1,000 working age } \\
\text { people }\end{array}$ & Fuzzy value \\
\hline Condition & VAE & $\begin{array}{l}\text { Continuous variable that represents the voice and accountability } \\
\text { for a particular context }\end{array}$ & Fuzzy value \\
\hline Condition & PVE & $\begin{array}{l}\text { Continuous variable that specifies the political stability } \\
\text { established in a specific country }\end{array}$ & Fuzzy value \\
\hline Condition & GEE & $\begin{array}{l}\text { Continuous variable that specifies the government effectiveness } \\
\text { of a region }\end{array}$ & Fuzzy value \\
\hline Condition & RQE & $\begin{array}{l}\text { Continuous variable that represents the regulatory quality for a } \\
\text { specific country }\end{array}$ & Fuzzy value \\
\hline Condition & RLE & $\begin{array}{l}\text { Continuous variable that specifies the rule of law established in } \\
\text { a particular context }\end{array}$ & Fuzzy value \\
\hline Condition & CCET & $\begin{array}{l}\text { Continuous variable that specifies the control of corruption in a } \\
\text { specific context }\end{array}$ & Fuzzy value \\
\hline
\end{tabular}


The FsQCA methodological approach is considered to be adequate in order to explore how these different conditions combine according to causal relations, the consequence being the outcome (Urueña et al., 2018; Gentina, Huarng \& Sakashita, 2018; Huarng \& Yu, 2019a). Raw data have been calibrated in fuzzy values according to Ragin's criteria (2008). Scores have been rescaled, ranging from 0.0 to 1.0 . In this way, cases for full membership and full non-membership have been identified. The process to transform raw data into fuzzy values is based on a calibration technique, which is carried out as follows: identification of thresholds for full membership ( $\geq 0.95)$; full non-membership $(\leq 0.05)$; and the crossover anchor (0.5). Table 2 presents the thresholds for the calibration.

Table 2. Calibration for outcome and conditions

\begin{tabular}{|l|c|c|c|}
\hline & \multicolumn{3}{|c|}{ Thresholds } \\
\hline & $\begin{array}{c}\text { Full } \\
\text { membership }\end{array}$ & $\begin{array}{c}\text { Cross- } \\
\text { over point }\end{array}$ & $\begin{array}{c}\text { Full non- } \\
\text { membership }\end{array}$ \\
\hline $\begin{array}{l}\text { Entrepreneurship } \\
\text { rate (success) }\end{array}$ & 9.88 & 2.153 & 0.255 \\
\hline $\begin{array}{l}\text { Voice and } \\
\text { accountability (VAE) }\end{array}$ & 1.397 & 0.432 & -0.856 \\
\hline $\begin{array}{l}\text { Political stability } \\
\text { (PVE) }\end{array}$ & 1.118 & 0.178 & -1.127 \\
\hline $\begin{array}{l}\text { Government } \\
\text { effectiveness (GEE) }\end{array}$ & 1.737 & 0.265 & -0.670 \\
\hline $\begin{array}{l}\text { Regulatory quality } \\
\text { (RQE) }\end{array}$ & 1.658 & 0.391 & -0.622 \\
\hline $\begin{array}{l}\text { Rule of law (RLE) } \\
\text { (CCET) }\end{array}$ & 3.387 & 2.425 & 0.560 \\
\hline $\begin{array}{l}\text { Control of corruption } \\
\text { (.75) }\end{array}$ & 0.098 & -0.808 \\
\hline
\end{tabular}

Note: As per Crilly et al. (2012) the values of 0.5 are dropped by the fsQCA 3.0 and are therefore replaced by 0.49 .

Theoretical support and previous knowledge are crucial to establish the fuzzy values according to the different calibrations (Ragin, 2008). However, percentiles are widely accepted in academia. (GarcíaCastro et al., 2013; Greckhamer et al., 2008; Khedhaouria \& Thurik, 2017; Woodside et al., 2016). Taking 
the study by Kraus et al. (2016) as a reference, we use breakpoints for full membership ( $90^{\text {th }}$ percentile), the cross-over point ( $50^{\text {th }}$ percentile), and full non-membership ( $10^{\text {th }}$ percentile).

Therefore, the breakpoints for outcome and conditions in this study have been established using the 90th, 50th and 10th percentiles (Kraus et al., 2016). In order to specify the calibration process for the outcome (entrepreneurship rate), the breakpoints for full membership (90th percentile), cross-over point (50th percentile) and full non-membership (10th percentile) have been identified with the values of 9.88 , 2.153 , and 0.255 , respectively. For the rest of the conditions we have also used percentiles, since they are fuzzy values.

All six conditions are indicators for institutional quality. Therefore, all of them are continuous variables which form a fuzzy-set condition depending on their specific characteristics. Voice and accountability (VAE) expresses the freedom of speech, of association and of the press in a particular context (Friedman, 2011); whereas political stability (PVE) represents the likelihood of a government to be destabilized (Seyoum \& Ramirez, 2019). The analysis of government effectiveness (GEE) expresses the quality of public and civil services, and the degree of their independence from political pressures. On the other hand, regulatory quality (RQE) reflects the government's ability to formulate and implement sound policies which promote private sector development (Yağc1, 2017). The rule of law (RLE) refers to the quality of contract enforcement, property rights, police, and court action, as well as to the likelihood of crime and violence (Levie \& Autio, 2011). Finally, the control of corruption (CCET) reflects the perception of the extent to which public power is exerted for private gain (Friedman, 2011). As mentioned, they all are fuzzy conditions, and the correspondent values assigned for the three taken percentiles have been contemplated in Table 2 .

\section{Results}

The fsQCA research methodology allows the identification of causal configurations which are prior to the success of the entrepreneurship rate, measured in the proportion of new entry businesses. The proposed model is:

MODEL A: Entrepreneurship rate = f $($ VAE,PVE,GEE,RQE,RLE,CCET $)$

Below are presented the results provided by fsQCA analysis, taking into account the contingency conditions that cause entrepreneurship success, which is expected to be the outcome of this study.

\subsection{Analysis of necessary conditions}

Once the different conditions and the outcome have been explained in detail, the next step is to proceed with the results obtained from fsQCA analysis (Huarng \& Yu, 2019b). Firstly, the potential occurrence of conditions necessary to the presence of the aforementioned outcome has been examined (see Table 3). Necessary conditions are the ones which must occur in order for the outcome to happen. In this sense, if the necessary condition analyzed is not present, the outcome cannot occur, which implies a failure when 
the condition is absent (Dul, 2016). All the conditions that are necessary have to be in any configuration that leads to the outcome. Alternatively, if this condition is not present, the successful result will fail. Most importantly, no other condition can replace the absence of a necessary condition. For this reason, it is highly relevant to analyze the necessary conditions. In this way, we consider a condition necessary when the consistency is higher than 0.9 (Schneider \& Wagemann, 2012).

As shown in Table 3, no condition exceeds the consistency cut-off of 0.9 for the presence of the outcome, expressed as entrepreneurship rate. For this reason, we may argue that no necessary condition applies to this analysis.

Table 3. Analysis of necessary conditions

\begin{tabular}{l|ll} 
& \multicolumn{2}{|c}{ Presence } \\
\hline & Cons.Nec & Cov.Nec \\
VAE & 0.775 & 0.692 \\
$\sim$ VAE & 0.446 & 0.405 \\
PVE & 0.823 & 0.702 \\
$\sim$ PVE & 0.408 & 0.388 \\
GEE & 0.804 & 0.724 \\
$\sim$ GEE & 0.430 & 0.386 \\
RQE & 0.824 & 0.739 \\
$\sim$ RQE & 0.426 & 0.385 \\
RLE & 0.804 & 0.726 \\
$\sim$ RLE & 0.432 & 0.387 \\
CCET & 0.467 & 0.410 \\
$\sim$ CCET & 0.792 & 0.731 \\
& & \\
\hline & &
\end{tabular}

\subsection{Analysis of sufficient conditions}

For this analysis, the consistency cut-off adopted amounts to 0.86 . Additionally, we have adopted the criteria specified by Rihoux and Ragin (2009), who claim that the cut-off should exceed 0.75 . Similarly, the frequency threshold for success has been established at 1 . By adopting this threshold, we have been able to include 76 cases in the analysis of conditions leading to success.

The fsQCA research methodology enables the analysis of causally-interrelated condition syntheses 
potentially leading to success, this being determined as the entrepreneurship rate. By following this approach, three different solutions may be obtained: complex, parsimonious, and intermediate. In this study, all three solutions have provided comparable results. The results are considered comparable because the sample used in this study is based on a relatively large collection of entrepreneurship rates in a wide range of countries (García-Castro et al., 2013). In Table 4, the parsimonious and the intermediate solution derived by the fsQCA approach may be observed. According to Crilly et al. (2012, p. 1349), a 'parsimonious solution is contained within an intermediate solution'. However, an intermediate solution is more conservative (Ragin, 2008) because it 'contains not only core conditions, but also peripheral conditions' (Crilly, 2011, p. 705).

The FsQCA approach is gaining relevance in studies within the social sciences. More concretely, the parsimonious solution is analyzed in pieces of marketing research, such as the studies conducted by Frösén et al. (2016). Alternatively, Pajunen (2008) has opted for this solution in studies on international business, and Skaaning (2011) and Thomann (2015) in broader social science settings. Most recently, Franklin and Marshall (2019), as well as Kraus et al., (2018) have adapted this method in managementoriented research. The results below are presented employing a study conducted by Fiss (2011).

Table 4. Analysis of sufficient conditions

\begin{tabular}{l|c|c|c|c|c|c|}
\hline \multirow{2}{*}{$\begin{array}{l}\text { Nonfiguration } \\
\text { No. }\end{array}$} & 1 & 2 & 3 & 4 & 5 & 6 \\
\hline VAE & $\circ$ & $\bullet$ & $\bullet$ & $\bullet$ & $\bullet$ & $\bullet$ \\
\hline PVE & $\bullet$ & & & $\circ$ & & $\bullet$ \\
\hline GEE & $\bullet$ & $\bullet$ & $\bullet$ & $\bullet$ & $\bullet$ & 0 \\
\hline RQE & & $\bullet$ & 0 & & & $\bullet$ \\
\hline RLE & $\bullet$ & $\circ$ & $\bullet$ & $\bullet$ & $\bullet$ & $\bullet$ \\
\hline $\begin{array}{l}\text { CCET } \\
\text { Coverage }\end{array}$ & 0.065 & 0.002 & 0.010 & 0.040 & 0.020 & 0.005 \\
\hline Raw coverage & 0.269 & 0.236 & 0.247 & 0.251 & 0.276 & 0.229 \\
\hline
\end{tabular}




\begin{tabular}{l|c|}
\hline $\begin{array}{l}\text { Solution } \\
\text { coverage }\end{array}$ & 0.422 \\
$\begin{array}{l}\text { Solution } \\
\text { consistency }\end{array}$ & 0.837 \\
\hline
\end{tabular}

Note: According to both Ragin's (2008), and Fiss' (2011) studies, the solutions have been grouped in regard with their 'core' structures, where: $\bullet$ black circles indicate the presence of the condition; $\bigcirc$ white circles indicate the absence of the condition; $\bullet \circ$ large circles indicate a core condition (i.e. it appears in both the parsimonious and the intermediate solution); $\bullet \circ$ small circles indicate that the condition only appears in the intermediate solution; blank spaces indicate that this condition may be present or absent (i.e. it is not relevant).

Taking Schneider et al.'s (2010) study, this model showing the success of the outcome is relevant, since the solution consistency exceeds 0.75 (0.837). In this line, both Ragin (2008) and Woodside (2012) claim that the threshold should be higher than 0.8. On the other hand, solution coverage, which measures the occurrence rates for the six configurations for successful entrepreneurship, is high $(0.422)$.

Looking specifically at each configuration, consistency measures in these cases the extent to which they represent subsets of the outcome. Therefore, it seems sensible to choose those configurations exceeding consistency values of 0.75 . Following this criteria, all configurations for successful entrepreneurship demonstrate sufficiency with respect to the entrepreneurship outcome, measured in terms of new entry businesses.

On its part, raw coverage measures the extent to which the configurations account for the outcome. Unique coverage measures the proportion within the final outcome of memberships explained by each individual configuration. The high coverage value indicates a configuration explaining a large proportion of the result for entrepreneurship success. All expressed configurations represent paths to successful entrepreneurship. Because all consistency values are superior to 0.8 (Fiss, 2011; Ragin, 2008), all configurations will be analyzed.

According to Configuration 1, 26.9\% of the cases suggest that entrepreneurship is higher when there is political stability, government effectiveness, and rule of law in a specific territory. Simultaneously, higher levels of entrepreneurship are achieved when there is no voice and accountability, and no control of corruption. This conclusion has a consistency level of 0.875 . Configuration 2 suggests that $23.6 \%$ of the cases determine higher entrepreneurship levels when there is voice and accountability, government effectiveness and regulatory quality for a specific country, and no rule of law or control of corruption. This conclusion has a consistency level of 0.866 . Configuration 3 expresses that $24.7 \%$ of the cases suggest a higher entrepreneurship when there is voice and accountability, government effectiveness, and rule of law. In this combination, the lack of regulatory quality and control of corruption also determine higher levels of entrepreneurship. This conclusion has a consistency level of 0.866 . 
According to Configuration 4, 25.1\% of the cases suggest that entrepreneurship is higher when there's no political stability, but there is voice and accountability, government effectiveness, and rule of law. This conclusion has a consistency level of 0.877 . Configuration 5 determines that $27.6 \%$ of the cases demonstrate entrepreneurship rates to be high when there is voice and accountability, government effectiveness, rule of law, but no control of corruption for a specific territory. The consistency level for this solution is 0.863 . Finally, according to Configuration $6,22.9 \%$ of the cases suggest that entrepreneurship levels are higher when there is voice and accountability, political stability, regulatory quality, and rule of law for a specific country. Simultaneously, higher levels of entrepreneurship may be achieved when there is no control of corruption. This conclusion has a consistency level of 0.879 .

\section{Conclusions}

Most studies researching the role of institutional quality in entrepreneurship have concluded that institutional quality affects entrepreneurship. Yet, in the vast majority of situations, the outcomes of institutional quality have been generalized, ignoring that institutional quality might influence entrepreneurship with different degrees of intensity depending on the level of entrepreneurship of the country, and thereby showing heterogeneous effects. This paper is the first to apply fsQCA approaches to explore the heterogeneous effects of institutional quality on entrepreneurship.

From a methodological approach, this research contributes to the study on institutional quality and entrepreneurship by employing the fsQCA method. With the application of this technique, we reach the conclusion that none of the variables itself leads to the outcome (successful entrepreneurship). Instead, the responsibility for getting the outcome are combinations of different conditions. FsQCA approach was used in this research to show all possible combinations of several conditions which are linked to our main research question: institutional quality and entrepreneurial success. Six different elements of institutional quality were carefully researched: voice and accountability, political stability, government effectiveness, regulatory quality, rule of law and control of corruption. Finally, a detailed analysis was conducted in order to evaluate the relevance of each institutional quality condition on the final combination determining entrepreneurial success.

The findings in the study show that entrepreneurial success is determined by the combination of the following conditions of institutional quality: voice accountability, political stability, regulatory quality and rule of law. Our results might also help to provide some policy implications. First, our work emphasizes the effectiveness of fsQCA regarding entrepreneurship, thus assisting researchers in accounting for inconsistent results in previous studies on institutional quality, or the impact of entrepreneurship nexus that may originate from research design issues. Next, our results suggest that institutional quality affects entrepreneurship and, therefore, policies promoting institutional quality would be considerably useful, especially for those countries showing high entrepreneurship levels, since it has a noticeable impact on entrepreneurship. Meanwhile, the findings of this study can also be applicable to lower-entrepreneurship-level countries wishing to promote higher rates of domestic entrepreneurship because establishing the degree of parameter heterogeneity can help policymakers to 
determine whether a particular policy in one country can be transferred to other countries.

\subsection{Limitations and future studies}

Although our study counts on several strengths, it also has some limitations requiring further study and exploration. The institutional quality dimensions that are taken as a reference in this study are obtained from the World Governance Indicators (WGI). However, based on our findings, we can highlight that other indicators could be used simultaneously in order to enrich the study from different approaches. It would be also interesting to conduct this study, bearing in mind the differences among countries in terms of GDP growth or government spending. Theoretically, and perhaps also empirically, it is important to analyze the motivation to become an entrepreneur, differentiating between opportunity and necessity entrepreneurship. In this line, this study measures the entrepreneurship levels in terms of new entry density. Additionally, it could be interesting to study the survival of companies in a short period of time (3-5 years) according to the institutional quality indicators (voice and accountability, political stability, government effectiveness, regulatory quality, rule of law and control of corruption). Therefore, further studies should try to provide some additional evidence on these respects.

Appendix A List of countries and regions (91)

\begin{tabular}{|c|c|c|c|}
\hline \multicolumn{4}{|c|}{ Countries/regions under Study } \\
\hline Albania & Finland & Mauritius & Singapore \\
\hline Algeria & France & Mexico & Slovak Republic \\
\hline Argentina & Georgia & Moldova & Slovenia \\
\hline Armenia & Germany & Mongolia & South Africa \\
\hline Australia & Ghana & Montenegro & Spain \\
\hline Austria & Hong Kong SAR, China & Morocco & Sri Lanka \\
\hline Azerbaijan & Hungary & Namibia & Sweden \\
\hline Bangladesh & Iceland & Nepal & Switzerland \\
\hline Belgium & India & Netherlands & Thailand \\
\hline Belize & Indonesia & Nigeria & Togo \\
\hline Bolivia & Ireland & North Macedonia & Tunisia \\
\hline Botswana & Israel & Norway & Turkey \\
\hline Brazil & Italy & Oman & Ukraine \\
\hline Bulgaria & Jamaica & Pakistan & United Arab Emirates \\
\hline Burkina Faso & Japan & Panama & United Kingdom \\
\hline Chile & Jordan & Paraguay & Uruguay \\
\hline Colombia & Kazakhstan & Peru & \\
\hline Costa Rica & Korea, Rep. & Philippines & \\
\hline Croatia & Kyrgyz Republic & Poland & \\
\hline Cyprus & Latvia & Portugal & \\
\hline Czech Republic & Lesotho & Russian Fed. & \\
\hline Denmark & Lithuania & Rwanda & \\
\hline
\end{tabular}




$\begin{array}{lll}\text { Dominican Rep. } & \text { Luxembourg } & \text { Senegal } \\ \text { El Salvador } & \text { Malaysia } & \text { Serbia } \\ \text { Estonia } & \text { Malta } & \text { Sierra Leone }\end{array}$

\section{References}

Angulo-Guerrero, M.J., Pérez-Moreno, S., \& Abad-Guerrero, I.M. (2017). How economic freedom affects opportunity and necessity entrepreneurship in the OECD countries. Journal of Business Research, 73, 30-37.

Aparicio, S., Urbano, D., \& Audretsch, D. (2016). Institutional factors, opportunity entrepreneurship and economic growth: Panel data evidence. Technological Forecasting and Social Change, 102, 45-61.

Arzubiaga, U., Iturralde, T., Maseda, A., \& Kotlar, J. (2018). Entrepreneurial orientation and firm performance in family SMEs: the moderating effects of family, women, and strategic involvement in the board of directors. International Entrepreneurship and Management Journal, 14(1), 217-244.

Asongu, S. A., Nwachukwu, J. C., \& Orim, S. M. I. (2018). Mobile phones, institutional quality and entrepreneurship in Sub-Saharan Africa. Technological Forecasting and Social Change, 131, 183-203.

Bao, Y., Miao, Q., Liu, Y., \& Garst, D. (2016). Human capital, perceived domestic institutional quality and entrepreneurship among highly skilled Chinese returnees. Journal of Developmental Entrepreneurship, 21(01), 1650002.

Barnett, W. A., Hu, M., \& Wang, X. (2019). Does the utilization of information communication technology promote entrepreneurship: Evidence from rural China. Technological Forecasting and Social Change, 141, 12-21.

Baron, R. A., \& Markman, G. D. (2018). Toward a process view of entrepreneurship: The changing impact of individual-level variables across phases of new firm development. In Current topics in management (pp. 45-63). Routledge.

Baumol, W.J. (1990). Entrepreneurship: Productive, unproductive and destructive. Journal of Political Economy, 98(5), 893-921.

Bercovitz, J., \& Feldman, M. (2008). Academic entrepreneurs: Organizational change at the individual level. Organization Science, 19(1), 69-89.

Bjørnskov, C., \& Foss, N.J. (2008). Economic freedom and entrepreneurial activity: Some crosscountry evidence. Public Choice, 134(3-4), 307-328.

Bourdieu, P. (2011). The forms of capital. (1986). Cultural Theory: An anthology, 1, 81-93.

Busenitz, L. W., Gomez, C., \& Spencer, J. W. (2000). Country institutional profiles: Unlocking entrepreneurial phenomena. Academy of Management Journal, 43(5), 994-1003.

Crilly, D. (2011). Predicting stakeholder orientation in the multinational enterprise: A mid-range theory. Journal of International Business Studies, 42(5), 694-717.

Crilly, D., Zollo, M., \& Hansen, M. T. (2012). Faking it or muddling through? Understanding decoupling in response to stakeholder pressures. Academy of Management Journal, 55(6), 1429-1448.

Cuervo, A. (2005). Individual and environmental determinants of entrepreneurship. The International Entrepreneurship and Management Journal, 1(3), 293-311. 
Del Bosco, B., Chierici, R., \& Mazzucchelli, A. (2019). Fostering entrepreneurship: an innovative business model to link innovation and new venture creation. Review of Managerial Science, 13(3), $561-574$.

DiMaggio, P. J., \& Powell, W. W. (1983). The iron cage revisited: Institutional isomorphism and collective rationality in organizational fields. American Sociological Review, 147-160.

Díaz-Casero, J., Ángel Manuel Díaz-Aunión, D., Cruz Sanchez-Escobedo, M., Coduras, A., \&

Fereidouni, H.G., \& Masron, T.A. (2012). Governance matters and entrepreneurial activities. Thunderbird International Business Review, 54(5), 701-712.

Dul, J. (2016). Identifying single necessary conditions with NCA and fsQCA. Journal of Business Research, 69(4), 1516-1523.

Escandon-Barbosa, D., Urbano-Pulido, D., \& Hurtado-Ayala, A. (2019). Exploring the relationship between formal and informal institutions, social capital, and entrepreneurial activity in developing and developed countries. Sustainability, 11(2)

Everett C. H. (1939). "Institutions" in An Outline of the Principles of Sociology, Robert E. Park, ed. New York: Barnes \& Noble.

Ferreira, J. J., Fernandes, C. I., \& Kraus, S. (2019). Entrepreneurship research: mapping intellectual structures and research trends. Review of Managerial Science, 13(1), 181-205.

Fischer, B. B., de Moraes, G. H. S. M., \& Schaeffer, P. R. (2019). Universities' institutional settings and academic entrepreneurship: Notes from a developing country. Technological Forecasting and Social Change, 147, 243-252.

Fiss, P. (2011). Building better causal theories: A fuzzy set approach to typologies in organization research. Academy of Management Journal, 54(2), 393-420.

Franklin, D., \& Marshall, R. (2019). Adding co-creation as an antecedent condition leading to trust in business-to-business relationships. Industrial Marketing Management, 77, 170-181.

Friedman, B. A. (2011). The relationship between governance effectiveness and entrepreneurship. International Journal of Humanities and Social Science, 1(17), 221-225.

Frösén, J., Luoma, J., Jaakkola, M., Tikkanen, H., \& Aspara, J. (2016). What counts versus what can be counted: The complex interplay of market orientation and marketing performance measurement. Journal of Marketing, 80(3), 60-78.

Fuentelsaz, L., González, C., \& Maicas, J.P. (2019). Formal institutions and opportunity entrepreneurship. The contingent role of informal institutions. Business Research Quarterly, 22(1), $5-24$.

Fuentelsaz, L., González, C., Maícas, J. P., \& Montero, J. (2015). How different formal institutions affect opportunity and necessity entrepreneurship. BRQ Business Research Quarterly, 18, 246-258.

Gao, Y., Ge, B., Lang, X., \& Xu, X. (2018). Impacts of proactive orientation and entrepreneurial strategy on entrepreneurial performance: An empirical research. Technological Forecasting and Social Change, 135, 178-187.

García-Castro, R., Aguilera, R. V., \& Ariño, M. A. (2013). Bundles of firm corporate governance practices: A fuzzy set analysis. Corporate Governance: An International Review, 21(4): 390-407.

Gentina, E., Huarng, K. H., \& Sakashita, M. (2018). A social comparison theory approach to mothers' 
and daughters' clothing co-consumption behaviors: A cross-cultural study in France and Japan. Journal of Business Research, 89, 361-370.

Globerman, S., \& Shapiro, D. (2002). Global foreign direct investment flows: The role of governance infrastructure. World Development, 30(11), 1899-1919.

Gómez-Haro, S., Aragón-Correa, J. A., \& Cordón-Pozo, E. (2011). Differentiating the effects of the institutional environment on corporate entrepreneurship. Management Decision, 49(10), 1677-1693.

Gonzalez-Garcia, J., Sotelo-Gonzalez, J., \& Zegarra-Saldaña, P. (2019). The sovereign debt crisis and national centripetal vs. regional centrifugal forces in political economy: empirical lessons from Spain. International Journal of Services Operations and Informatics, 10(1), 1-16.

Greckhamer, T., Misangyi, V. F., Elms, H., \& Lacey, R. (2008). Using qualitative comparative analysis in strategic management research: An examination of combinations of industry, corporate, and businessunit effects. Organizational Research Methods, 11(4), 695-726.

Herrera-Echeverri, H., Haar, J., \& Estévez-Bretón, J.B. (2014). Foreign direct investment, institutional quality, economic freedom and entrepreneurship in emerging markets. Journal of Business Research, 67(9), 1921-1932.

Huarng, K. H., \& Yu, M. F. (2019a). Customer satisfaction and repurchase intention theory for the online sharing economy. Review of Managerial Science, 13(3), 635-647.

Huarng, K. H., \& Yu, T. H. K. (2019b). A comparative study of online consumer behavior: a tale of two research methods. International Journal of Emerging Markets. In press.

Ilg, P. (2019). How to foster green product innovation in an inert sector. Journal of Innovation \& Knowledge, 4(2), 129-138.

Kang, Q., Li, H., Cheng, Y., \& Kraus, S. (2019). Entrepreneurial ecosystems: analyzing the status quo. Knowledge Management Research \& Practice, 1-13.

Kaufmann, D., Kraay, A., \& Mastruzzi, M. (2009). Governance matters VIII: Aggregate and individual governance indicators 1996-2008. The World Bank.

Khedhaouria, A., \& Thurik, R. (2017). Configurational conditions of national innovation capability: A fuzzy set analysis approach. Technological Forecasting and Social Change, 120, 48-58.

Kraus, S., Ribeiro-Soriano, D., \& Schüssler, M. (2018). Fuzzy-set qualitative comparative analysis (fsQCA) in entrepreneurship and innovation research - the rise of a method. International Entrepreneurship and Management Journal, 14(1), 15-33.

Kraus, S., Richter, C., Brem, A., Cheng, C. F., \& Chang, M. L. (2016). Strategies for reward-based crowdfunding campaigns. Journal of Innovation \& Knowledge, 1(1), 13-23.

Kraus, S., Breier, M. \& Dasí-Rodríguez, S. (2020). The art of crafting a systematic literature review in entrepreneurship research. International Entrepreneurship and Management Journal. In press.

Bolton, D.L. , \& Lane, M. D. (2012). Individual entrepreneurial orientation: Development of a measurement instrument. Education+ Training, 54(2/3), 219-233.

Levie, J., \& Autio, E. (2011). Regulatory burden, rule of law, and entry of strategic entrepreneurs: An international panel study. Journal of Management Studies, 48(6), 1392-1419.

Litschka, M., \& Pellegrini, T. (2019). Considerations on the governance of open data - an institutional economic perspective. International Journal of Intellectual Property Management, 9(3-4), 247-263. 
Nikolaev, B.N., \& Wood, M.S. (2018). Cascading ripples: Contagion effects of entrepreneurial activity on self-employment attitudes and choices in regional cohorts. Strategic Entrepreneurship Journal, 12(4), 455-481.

Nina Gunnerud, B. (1997). Gender, place and entrepreneurship. Entrepreneurship \& Regional Development, 9(3), 259-268.

North, D.C. (1990). Institutions, institutional change and economic performance. Cambridge: Cambridge University Press.

North, D. C. (1993). Toward a theory of institutional change. Political economy: Institutions, Competition, and Representation, 31(4), 61-69.

Nyström, K. (2008). The institutions of economic freedom and entrepreneurship: evidence from panel data. Public Choice, 136(3-4), 269-282.

Pajunen, K. (2008). Institutions and inflows of foreign direct investment: A fuzzy-set analysis. Journal of International Business Studies, 39(4), 652-669.

Parsons, T. (1990). Prolegomena to a theory of social institutions. American Sociological Review, 55(3), 319-333.

Pejic Bach, M., Aleksic, A., \& Merkac-Skok, M. (2018). Examining determinants of entrepreneurial intentions in Slovenia: applying the theory of planned behaviour and an innovative cognitive style. Economic Research-Ekonomska Istraživanja, 31(1), 1453-1471.

Peres, M., Ameer, W., \& Xu, H. (2018). The impact of institutional quality on foreign direct investment inflows: evidence for developed and developing countries. Economic Research-Ekonomska Istraživanja, 31(1), 626-644.

Ponce, R. S., Cancio, J. A. P., \& Sánchez, J. E. (2018). The capabilities approach and values of sustainability: Towards an inclusive Pedagogy. Journal of Innovation \& Knowledge, 3(2), 76-81.

Ragin, C. (2008). Redesigning Social Inquiry: Fuzzy Sets and Beyond. University of Chicago, IL: Chicago Press.

Rihoux, B., \& Ragin, C. C. (2009). Configurational Comparative Methods. Sage, Thousand Oaks, CA.

Roig-Tierno, N., Kraus, S. \& Cruz, S. (2018). The relation between coopetition and innovation/entrepreneurship. Review Managerial Science, 12 (2), 379-383.

Schumpeter, J. A. (2000). Entrepreneurship as innovation. Entrepreneurship: The social science view, $51-75$.

Schneider, C. Q., \& Wagemann, C. (2012). (Eds.) Set-theoretic methods for the social sciences: A guide to qualitative comparative analysis. Cambridge: Cambridge University Press.

Schneider, M. R., Schulze-Bentrop, C., \& Paunescu, M. (2010). Mapping the institutional capital of high-tech firms: A fuzzy-set analysis of capitalist variety and export performance. Journal of International Business Studies, 41(2), 246-266.

Scott, W. R. (1994). Institutions and organizations: Toward a theoretical synthesis. Institutional environments and organizations: Structural complexity and individualism, 55-80.

Scott, W. R. (2005). Institutional theory: Contributing to a theoretical research program. Great minds in management: The process of theory development, 37(2005), 460-484. 
Selznick, P. (1949). TVA and the grass roots: A study in the sociology of formal organization (Vol. 3). Univ of California Press.

Semrau, T., Ambos, T., \& Kraus, S. (2016). Entrepreneurial orientation and SME performance across societal cultures: An international study. Journal of Business Research, 69(5), 1928-1932.

Seyoum, B., \& Ramirez, J. (2019). Economic freedom and trade flows: A moderated mediation model of inward foreign direct investment (FDI) and government stability. Journal of Economic Studies, 46(4), 985-006.

Shan, S., Jia, Y., Zheng, X., \& Xu, X. (2018). Assessing relationship and contribution of China's technological entrepreneurship to socio-economic development. Technological Forecasting and Social Change, 135, 83-90.

Skaaning, S. E. (2011). Assessing the robustness of crisp-set and fuzzy-set QCA results. Sociological Methods \& Research, 40(2), 391-408.

Sobel, R. S. (2008). Testing Baumol: Institutional quality and the productivity of entrepreneurship. Journal of Business Venturing, 23(6), 641-655.

Sobel, R. S., Clark, J. R., \& Lee, D. (2007). Freedom, barriers to entry, entrepreneurship, and economic progress. The Review of Austrian Economics, 20(4), 221-236.

Stephan, U., \& Uhlaner, L. M. (2010). Performance-based vs socially supportive culture: A crossnational study of descriptive norms and entrepreneurship. Journal of International Business Studies, 41(8), 1347-1364.

Thomann, E. (2015). Is output performance all about the resources? A fuzzy-set qualitative comparative analysis of street-level bureaucrats in Switzerland. Public Administration, 93(1), 177-194.

Urban, B. (2016). Empirical evidence on the influence of the institutional environment on venture innovation performance in South Africa. Journal of Developmental Entrepreneurship, 21(02), 1650011.

Urbano, D., \& Alvarez, C. (2014). Institutional dimensions and entrepreneurial activity: an international study. Small Business Economics, 42(4), 703-716.

Urbano, D., Aparicio, S., \& Audretsch, D. B. (2019). Institutional Context, Entrepreneurial Activity, and Social Progress. In Institutions, Entrepreneurship, and Economic Performance (pp. 131-149). Springer, Cham.

Urueña, A., E Arenas, Á., \& Hidalgo, A. (2018). Understanding workers' adoption of productivity mobile applications: a fuzzy set qualitative comparative analysis (fsQCA). Economic ResearchEkonomska Istraživanja, 31(1), 967-981.

Valliere, D., \& Peterson, R. (2009). Entrepreneurship and economic growth: Evidence from emerging and developed countries. Entrepreneurship \& Regional Development, 21(5-6), 459-480.

Welter, F. (2005). Entrepreneurial behavior in differing environments. In Local heroes in the global village (pp. 93-112). Springer, Boston, MA.

Welter, F., \& Smallbone, D. (2011). Institutional perspectives on entrepreneurial behavior in challenging environments. Journal of Small Business Management, 49(1), 107-125.

Woodside, A. G. (2012). Incompetency training: Theory, practice, and remedies. Journal of Business Research, 65(3), 279-293.

Woodside, A. G., Bernal, P. M., \& Coduras, A. (2016). The general theory of culture, entrepreneurship, 
innovation, and quality-of-life: Comparing nurturing versus thwarting enterprise start-ups in BRIC, Denmark, Germany, and the United States. Industrial Marketing Management, 53, 136-159.

Yağc1, M. (2017). Institutional entrepreneurship and organisational learning: financial stability policy design in Turkey. Policy and Society, 36(4), 539-555. 